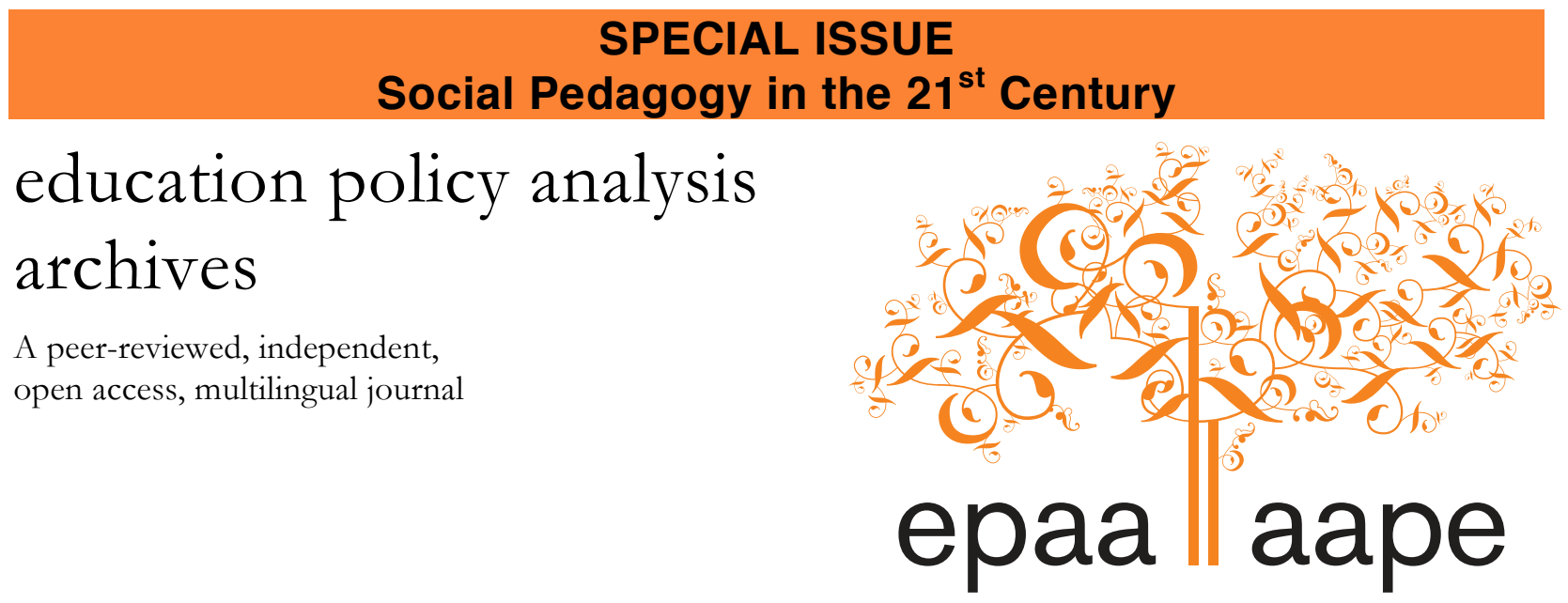

Arizona State University

ISSN 1068-2341

\title{
Las políticas de lucha contra la exclusión social y su relación con la Pedagogía Social: Los programas de Rentas Mínimas de Inserción y la propuesta de las Rentas Básicas.
}

\author{
Juan Ramón Rodríguez Fernández. \\ Consejería de Bienestar Social del Principado de Asturias \\ España
}

Citación: Citación: Rodríguez, J. R. (2013). Las políticas de lucha contra la exclusión social y su relación con la Pedagogía Social: Los programas de Rentas Mínimas de Inserción y la propuesta de las Rentas Básicas. Archivos Analíticos de Políticas Educativas, 21(40). Recuperado [data] http://epaa.asu.edu/ojs/article/view/1243 Este artículo es parte del número especial de EPAA/AAPE sobre Pedagogia Social en el siglo 21 editado por Daniel Schugurensky y Michael Silver

Resumen: Las Rentas Mínimas de Inserción (RMI) son uno de los programas asistenciales más importantes dentro de las políticas de lucha contra la exclusión social de los Estados de Bienestar (EB). Frente a este tipo de programas herederos del pensamiento liberal, se defiende en este trabajo la Renta Básica (RB) como un instrumento que participa dentro de una estrategia global de carácter anticapitalista y no como una herramienta asistencial de lucha contra la pobreza. Por tanto, la Pedagogía Social asumirá un enfoque, unas prácticas, unos contenidos, unos fines... muy diferentes según se sitúe en la óptica de las RMI o en la de las RB. Desde la perspectiva de las RB y del pensamiento del que éstas beben (anarquismo y marxismo de corte solidario) la Pedagogía Social se dirige al cuestionamiento crítico del orden social, a la ruptura con las concepciones bancarias de la educación, la relación entre educación y trabajo, a la creación de prácticas que favorezcan la participación democrática directa del sujeto, etc. 
Palabras-clave: Rentas Básicas; Rentas Mínimas de Inserción; Pensamiento social crítico; Políticas de lucha contra la pobreza; Análisis del Discurso Educativo; Formación del profesorado.

\section{Politics against social exclusion and their relation with Social Pedagogy: Guaranteed Minimum Income programs and Basic Income.}

Abstract: This paper discusses the role of social pedagogy in the context of struggles for economic and political democracy, particularly regarding Guaranteed Minimum Income (GMI) programs, which are some of the most significant policy initiatives to combat social exclusion in modern Welfare States. The author argues that a more effective alternative to these programs, which are rooted in liberal thought, is a Basic Income (BI) model. Not to be confused with a charity instrument against poverty, BI is a tool in a broader anticapitalist strategy. Whether it operates in the context of GMI or BI, social pedagogy will have different expressions, goals, approaches and practices. In the context of BI and its ideological roots in Anarchist and solidarity Marxism, social pedagogy can critically address issues such as social inequalities, banking education, the relationship between education and work, and direct democracy.

Keywords: Basic Income; Guaranteed Minimum Income; Critical thought; Policies against poverty; Educational discourse analysis; Teacher training.

\section{Políticas na luta contra a exclusão social e sua relação com a pedagogia Social: os} programas de renda mínima de inserção e a proposta de uma renda básica.

Resumo: A renda mínima de inserção (RMI) é um dos mais importantes programas no âmbito da política na luta contra a exclusão social dos Estados de Bem-estar (EB). Contra este tipo de programas herdeiros do pensamento liberal, é defendida neste trabalho, a renda básica (RB) como um instrumento que participa numa estratégia global de caráter anticapitalista e não como um instrumento de bem-estar de redução da pobreza. Por tanto, a pedagogia social vai assumir uma abordagem, conteúdos, práticas, efeitos... muito diferentes na óptica do RMI ou na óptica do RB. Do ponto de vista das RB e o pensamento que eles bebem (anarquismo e marxismo de corte de solidariedade) pedagogia social enfoca o questionamento crítico da ordem social, a ruptura com as concepções bancária da educação, a relação entre educação e trabalho, para a criação de práticas que favoreçam a participação democrática direta da pessoa, etc.

Palavras-chave: Renda Básica; Renda Mínima de Inserção; Pensamento crítico social; Políticas de redução da pobreza; Analise do discurso educacional; formação de professores.

\section{Introducción}

El desarrollo de los Estados de Bienestar (EB) a lo largo del primer tercio del siglo XX surge tanto como un logro ante las luchas y las reivindicaciones de la clase trabajadora, como a su vez por una necesidad del propio sistema capitalista para desarrollarse y legitimarse como sistema de pensamiento hegemónico ante las amenazas de los sistemas comunistas de los países del Este (Bourdieu, 2000). En este sentido, los EB con su énfasis en la redistribución y en el establecimiento de unos niveles mínimos de calidad de vida (sanidad, educación y seguridad social), se pueden considerar como una respuesta liberal ante un problema denunciado por el pensamiento socialista.

La Pedagogía social en cuanto disciplina científica y práctica profesional se ha desarrollado profundamente vinculada al seno de las instituciones y prácticas que surgieron en los EB. Por ello, 
en su desempeño profesional siempre ha existido una ambivalencia entre el mantenimiento del orden social establecido y la legitimación por parte de la justicia social burguesa de las desigualdades sociales; y por otro, la lucha por una emancipación social y por una sociedad más justa e igualitaria que rompa con las desigualdades que impone el sistema capitalista. La propuesta que en estas líneas propongo sigue este último camino de la pedagogía social y transita los senderos desarrollados por el pensamiento social y educativo crítico: compromiso con los marginados y los oprimidos, defensa de una sociedad más justa e igualitaria y práctica socioeducativa de carácter contrahegemónica.

Parece evidente, siguiendo a Amin (2009), que ante la magnitud y extensión de la crisis capitalista mundial en sus diferentes dimensiones económica, social, política, ecológica, etc. Que el pensamiento liberal ha alcanzado sus límites y que podemos caracterizarlo como en situación terminal. Situación terminal que se puede aplicar a buena parte de las instituciones generadas por este pensamiento, entre ellas la escuela y las políticas sociales de lucha contra la pobreza y en general todas las actuaciones y programas que se han gestado en los EB. Ante esta situación de crisis terminal del pensamiento liberal, o como otros autores han señalado del pensamiento moderno (Silva, 2001), creo que es necesario plantear discursos, propuestas y prácticas contrahegemónicas que hagan frente a la avalancha neoliberal y que se orienten a la consecución de un mundo más justo y solidario.

En el ámbito de las políticas sociales de lucha contra la pobreza, los EB han tratado de abordarla fundamentalmente mediante acciones de tipo asistencial, benéfico y caritativo por ejemplo a través de los programas de Rentas Mínimas de Inserción Social (RMI). Su éxito en este sentido ha sido, por la propia naturaleza del pensamiento liberal y por las características de estos programas de rentas mínimas, bastante limitado ${ }^{1}$. Estos programas en consonancia con el discurso liberal conllevan una serie de concepciones determinadas sobre la idea de Sujeto, de Sociedad, de Educación, de Participación social, etc. Concepciones que como veremos se alinean dentro de la perspectiva del pensamiento liberal, bien sea en su faceta de corte ilustrada como en la socialdemocracia o bien en su faceta más neoliberal, siendo esta última la actualmente hegemónica.

Frente a este tipo de enfoques asistenciales de lucha contra la pobreza, defiendo la Renta Básica (Van Parjis, 1988 y 1995; Lo Vuolo, 1995; Iglesias Fernández, 1998, 2003, 2004; Raventós Pañella, 1999, etc.) como una propuesta alternativa que se asienta en principios opuestos a los señalados por el pensamiento de corte liberal. Propuesta que resulta especialmente antagónica al pensamiento hegemónico bajo la interpretación que de ella realiza, entre otros, el economista crítico español José Iglesias Fernández. El apartado segundo de esta colaboración se dedica a la explicación y desarrollo de las características de esta propuesta de redistribución social de la riqueza, que a diferencia de los planteamientos anteriores de RMI no se centra únicamente en la lucha contra pobreza, sino que se engloba dentro de una estrategia anticapitalista de transformación social de carácter más amplio ${ }^{2}$ (Iglesias Fernández, 2003; Martínez, 2002, etc.)

\footnotetext{
${ }^{1}$ Sirva de prueba que en el contexto español los niveles de pobreza se han mantenido estables en torno al 20\% desde hace más de 3 décadas (Lo Vuolo y Raventós, 2009; Iglesias Fernández, 2010, p. 103), reduciéndose únicamente los niveles de pobreza extrema o absoluta.

${ }^{2}$ La propuesta de las RB ha sido justificada teóricamente desde diversas posiciones ideológicas. Según Raventós Pañella (1999): desde posiciones cercanas al pensamiento neoliberal, como la Teoría propietarista de Nozick (1974), a posiciones de corte socialdemócrata como en el Liberalismo igualitario de Rawls (1995). Frente a estas interpretaciones, en esta colaboración, se defiende una interpretación anticapitalista de la RB, que se apoye en el pensamiento anarquista y marxista solidario. Por supuesto, según nos situemos en una interpretación u otra de la RB, su concreción, sus fines y el modelo de sociedad y sujeto variarán enormemente.
} 
Bajo esta propuesta de las Rentas Básicas (RB), la Pedagogía social se abre a otros horizontes, diferentes a los creados en las instituciones típicas de los $\mathrm{EB}$, y se relaciona con aspectos como la participación democrática popular, con otras maneras de entender la acción educativa, con una visión diferente de la Sociedad, del Sujeto, con el cuestionamiento del orden social, etc. El último apartado de este texto se dirigirá a apuntar las diferentes concepciones que sobre la acción socioeducativa tienen las RMI y las RB. Para su análisis seguiré la perspectiva que ofrece el análisis político del discurso educativo, en concreto los trabajos de Cascante (2005, 2007, etc.)

\section{La atención a la pobreza desde el pensamiento liberal: Las Rentas Mínimas de Inserción Social}

Para el pensamiento liberal, tanto en su versión social-ilustrada como en su versión neoliberal, el sujeto desarrolla sus capacidades y cubre sus necesidades fundamentalmente en el mercado (Isuari, Lo Vuolo y Tenti Fanfani, 1991) trabajando y ganando un salario con el que poder comprar bienes y servicios que cubran en última instancia sus necesidades básicas. El mercado es visto como el ámbito privilegiado en el que el sujeto mejor desarrolla sus capacidades, su naturaleza esencial y en donde alcanza su plenitud, por lo que desde la perspectiva liberal se trata, entonces, de extrapolar la lógica mercantilista a todos los ámbitos de la vida individual y social. Por cuanto es la supuesta neutralidad que ofrece el mercado donde las personas más capaces, las más emprendedoras, las más formadas educativamente demostrarán su valía en forma de elecciones adecuadas dentro de las posibilidades que el mercado ofrece. Aparece así el imaginario neoliberal del bomo economicus, que según la teoría de la elección individual y racional, elige libremente dentro de las diversas opciones que le ofrece el mercado, con el fin de maximizar su beneficio personal. Desde estas premisas, la intervención del Estado ha de ser reducida al mínimo para no limitar la iniciativa individual del sujeto, ni poner trabas al funcionamiento del libre mercado ${ }^{3}$ (Nozick, 1974).

Únicamente cuando el sujeto no es capaz de satisfacer sus necesidades básicas en el seno del mercado, es cuando el EB actúa para dar cobertura a tales necesidades a través de las distintas instituciones y políticas sociales.

Es en la relación con el mercado laboral donde se originan los grupos llamados de riesgo social, como aquellos sujetos que por sus propias características no pueden acceder al mercado, o son rechazados por él. En el caso de las personas adultas: ancianos, personas enfermas, con discapacidad, sin las credenciales formativas requeridas por el sistema productivo, etc. Todas ellos tienen una serie de características que les impiden o les dificultan vender su fuerza de trabajo a cambio de un salario.

La pobreza y la exclusión social son, desde este punto de vista liberal, una cuestión de responsabilidad individual y no un fenómeno social cuya base sea estructural ${ }^{4}$. Por ello el tipo de actuaciones por parte de los poderes públicos, del EB, para paliar estas problemáticas deben caracterizarse por ser: Individuales, asistenciales y focalizadas en grupos de riesgo. Estas características son las que conforman el marco en el que se diseñan las actuaciones y programas en materia de lucha contra la exclusión social. Marco en el que debido a la hegemonía neoliberal cada vez hay una mayor tendencia a la supresión de ayudas públicas, al endurecimiento a su acceso, a la

\footnotetext{
${ }^{3}$ Es decir, una Democracia Minima (Hayeck, 1985), que no contravenga el funcionamiento del mercado. Únicamente se acepta su intervención cuando se dirige a mantener las necesidades de la lógica mercantilista. ${ }^{4}$ Como afirma el candidato republicano Mitt Rommey a la presidencia de EEUU: "Mi trabajo no consiste en preocuparme por esas personas (en referencia los trabajadores pobres y a los beneficiarios de ayudas sociales). Nunca las convenceré de que deben asumir sus responsabilidades personales y ocuparse de su vida." (Citado en Krugman, 2012)
} 
privatización de servicios y al tratamiento punitivo de la pobreza. Es decir, a un desmantelamiento de los servicios sociales públicos EB y a una reordenación del mismo hacia la figura del EstadoEmpresario (Santos, 2008)

\section{¿Cómo atiende el EB a estos colectivos “en riesgo de exclusión social”?}

En el contexto español -y de forma similar en el europeo-, mediante una amalgama de heterogéneas prestaciones económicas que han ido surgiendo en los últimos años y que van desde las pensiones contributivas por jubilación, hasta las diversas prestaciones asistenciales (Arriba González de Durana, Parrilla Fernández y Pérez Eransus, 2009). Uno de estos programas de carácter asistencial directamente dirigido a la lucha contra la exclusión social y la pobreza es el de las Rentas Mínimas de Inserción Social, programa que se fue desarrollando de forma heterogénea a lo largo de la década de los años 90 en todo el territorio español.

Las RMI al ser de competencia autonómica han tenido un desarrollo muy desigual en el conjunto del territorio español, sin embargo todas ellas tienen en común la siguiente estructura (Arriba González de Durana, 2007):

- Una cuantía económica que ronda los 350 euros de media en el módulo básico (Ídem, 2007), con incrementos económicos según el tamaño de la unidad familiar.

- Un itinerario individualizado en el que se programan actividades dirigidas a la inserción socio-laboral de la persona beneficiaria de la prestación social.

El éxito de este tipo de programas ha sido muy limitado por varias razones, en primer lugar por la pobre financiación que estos programas tienen, haciendo cierto el dicho de que las políticas sociales para pobres son políticas pobres. En este sentido parece dudoso que con 350 euros sea posible cubrir las necesidades básicas, máxime cuando solamente el alquiler de una vivienda ya supera fácilmente esa cantidad. Más bien este tipo de programas se dirige al control social de la pobreza y a evitar el escándalo público por la cronicidad de la pobreza en nuestras sociedades ${ }^{5}$.

La condicionalidad de la percepción económica a la firma de un itinerario personalizado contribuye a soslayar el carácter estructural en donde se generan las condiciones de pobreza y focaliza en el propio sujeto la responsabilidad individual en su inserción (Arriba González de Durana, Parrilla Fernández y Pérez Eransus, 2009). De modo que si la persona no consigue insertarse a través del itinerario, es porque o bien tienen unos déficits personales que le hacen inempleable o, peor aún, porque simplemente ésta no quiere. De este modo en nuestras sociedades neoliberales, se pasa rápidamente de la atención caritativa al pobre a su castigo punitivo y a la criminalización de la pobreza (Wacquant, 2000 y 2010).

Las RMI son un instrumento heredero del pensamiento liberal y comparten rasgos de los dos discursos en los que actualmente se mueve el debate hegemónico. Por un lado son herederas del pensamiento social-ilustrado, ya que tratan desde la intervención pública suavizar y regular las desigualdades sociales que crea la lógica capitalista y el funcionamiento de los mercados económicos. Para ello se basan en el desarrollo de políticas sociales públicas más o menos guiadas por los principios de redistribución, universalidad y solidaridad, que cristalizaron en el desarrollo de los Estados de Bienestar Social en los países capitalistas avanzados. Son políticas que si bien no cuestionan abiertamente el sistema capitalista, sí que tratan de suavizar sus consecuencias en una suerte de capitalismo de rostro humano. Pero por otro lado, también tienen influencias del pensamiento neoliberal al enfatizar la responsabilidad individual del sujeto en el éxito o fracaso de su proceso de

5 “...la RMI es un tipo de asalarización de la pobreza, dirigida más bien a evitar el escándalo público de la pobreza y al control social de la misma”. (Negri, 1998, p. 46). 
inserción y al vincularlas explícitamente a la búsqueda activa de empleo y a la aceptación de cualquier tipo de oferta de trabajo (políticas de activación o workfare).

\section{Atención social burocrática y violencia simbólica}

Este tipo de enfoques de atención a la pobreza se caracterizan por el desarrollo de una compleja e intrincada burocracia, tanto en el ámbito administrativo como en el propio de intervención social. Burocracia en forma de departamentos, áreas, procedimientos, formularios, etc. que les dan sostén y en donde se llevan a cabo las intervenciones sociales técnicas. Un amplio abanico de profesionales aparecen en este espectro de la pedagogía social: pedagogos, psicólogos, sociólogos, trabajadores sociales, educadores, abogados, maestros y un largo etc.

Los diversos profesionales que se ubican en este ámbito suelen desempeñar una labor caracterizada fundamentalmente por una gestión de los recursos sociales existentes. El trabajador es un gestor técnico de recursos, quedando en un segundo plano la labor pedagógica de la acción social, la reflexión sobre la propia práctica profesional y desapareciendo del horizonte intelectual del trabajador/a aquellas cuestiones más cercanas a la emancipación social o al pensamiento crítico con respecto a lo que se hace en el día a día. Es decir, se acaban naturalizando las tareas del día a día y empobreciendo la capacidad para reflexionar y problematizar nuestra práctica laboral.

El trabajo social desde este prisma técnico de gestión legitima una función de control social y de estigmatización de la pobreza en una suerte de panóptico social (Foucault, 1979). En este sentido destaco:

a) el desarrollo de multitud de cuestionarios, fichas o protocolos. En los que se consigna información de todo tipo: datos personales, familiares, sociales, económicos, etc.

b) el control del (in)cumplimiento de las tareas suscritas en el itinerario individual y

en el mantenimiento de los requisitos para seguir siendo beneficiario de la RMI. Se somete a la persona a una observación y un escrutinio constante por parte de los servicios sociales. En acciones panópticas en el sentido foucaultiano que no son simplemente de vigilancia y control, sino que también estigmatizan y enjuician los modos de vida de las personas sobre las que se aplican $^{6}$.

Podemos ver en estos dispositivos sociales de beneficencia pública, de acuerdo con Foucault (2008) la articulación de dos tipos de poder. Por un lado, un poder de corte más coercitivo que controla y observa a los sujetos, que los aparta y excluye del resto de la población y que eventualmente los castiga. Poder que toma cuerpo en los instrumentos de recogida de información, en el cumplimiento de las acciones y objetivos de los itinerarios personalizados, en el desarrollo de técnicas psicosociales de intervención, etc. Por otro lado, un poder no tanto dirigido a la observación y supervisión del sujeto, sino a la regulación de su comportamiento. Un poder que no necesite ser ejercido de forma constante y externa sobre el sujeto, sino que se oriente a la interiorización de normas y a la autoregulación de la conducta.

El escaso éxito de estos programas de RMI en la erradicación de la pobreza, así como su creciente vinculación a la activación laboral (workfare), -¿por qué tanto énfasis en la formación para la inserción laboral, en la formación como capital humano subyugada a las demandas del sistema

\footnotetext{
${ }^{6} \mathrm{La}$ información que se recoge en los informes sociales sobre estructura familiar, sobre si se tiene pareja o no, sobre hábitos de vestimenta, higiene, consumo..., conlleva de por sí juicios implícitos y explícitos al establecer una comparativa entre los modelos normales, estándar y adecuados frente a los irregulares, atípicos y anormales.
} 
productivo, si no hay trabajo disponible? ${ }^{7}$. En este sentido, es necesario desmontar la idea neoliberal, pero también compartida por el pensamiento liberal-ilustrado, por la cual se considera que el aumento de la formación en cuanto a volumen y a calidad de titulados tiene un efecto positivo en el mercado de trabajo en la creación de puestos de trabajo. En otras palabras, no porque la ciudadanía tenga más niveles formativos, va haber más puestos de trabajo disponibles, ni vamos a tener una sociedad más justa ${ }^{8}$.

Por estos motivos se hace más relevante que nunca el proponer modos diferentes de reflexión y de actuación, modos que no se dirijan a la pobreza como la gran lacra social que hay que eliminar, sino planteamientos que superen el marco liberal-ilustrado en el que se gestaron los EB -y sus políticas sociales- y que se integren dentro de una estrategia global de carácter contrahegemónico.

\section{Un planteamiento contrahegemónico para el Siglo XXI: La Renta Básica}

La RB es una propuesta que no se limita a modificar o mejorar las políticas sociales de lucha contra la pobreza, sino que se orienta a una profunda transformación política y social a través de una mayor y mejor redistribución de la riqueza entre toda la ciudadanía. Siguiendo a Iglesias Fernández (2003) la RB se integra dentro de una estrategia global en la que se vincula la lucha contra la pobreza con la emergencia de nuevas formas de relación entre las personas y con la naturaleza y a prefigurarlas en la propia práctica reivindicativa. Básicamente se puede conceptualizar como el derecho de toda persona, por el hecho de ser ciudadano y ciudadana, a recibir un ingreso económico individual (Wright, 1997 y 2001). Siendo sus características estructurales básicas, dentro de las diferentes formas de interpretar las rentas básicas, las de ser un ingreso individual, universal e incondicional (Van Parijs, 1988 y 1995; Iglesias Fernández, 1998, 2003 y 2004; Raventós Panella, 1999): Individual: La prestación se dirige a la persona en cuanto a su condición de ciudadano y no se dirige a la unidad familiar como hacen habitualmente las prestaciones económicas dentro de los programas de lucha contra la pobreza.

Universal: Se configura como un derecho reconocido a todas las personas, independientemente de su situación, edad, sexo, etc.

Incondicional: Se trata de una prestación cuya percepción es independiente de la situación laboral de la persona, de los ingresos que ésta pueda tener y que se desvincula de la obligatoriedad de insertarse en el mercado laboral capitalista.

Contraponiendo las características de las RMI con las de las RB vemos que las primeras, al igual que otras prestaciones sociales como los subsidios por desempleo, incumplen estos tres requisitos básicos de las RB. En primer lugar, porque se dirigen a la unidad familiar y no a la persona de forma individual; en segundo lugar porque el derecho a su percepción está limitado a una serie de requisitos previos por parte de la persona, por lo que no es universal. Y en tercer lugar, porque se establecen

\footnotetext{
7 Siguiendo a Lo Vuelo, Raventós y Yanes, (2010) desde el inicio de la crisis económica mundial se han producido más de 30 millones de desempleados. En España el porcentaje de desempleo es del 26\% con casi seis millones de parados (El País, 2013)

8 "En los últimos años en los países capitalistas avanzados se da una creciente precariedad de los empleos. Jóvenes con altas calificaciones profesionales se ven abocados a trabajos discontinuos, mal pagados, con contratos (cuando existen) que no son más que explotación legalizada. El retroceso en los derechos de los trabajadores que se ha producido a partir de los años ochenta no es consecuencia de deficiencias de formación, lo que ha ocurrido es que desde entonces la correlación de fuerzas entre el mundo del capital y el del trabajo ha cambiado de forma muy importante a favor de las del capital." (Cascante Fernández, 2008, p. 29)
} 
una serie de contraprestaciones y obligaciones para su disfrute -itinerarios individualizados de inserción-, obligaciones cada vez más enfocadas explícitamente a la inserción laboral de la persona y con un carácter cada vez más coercitivo y punitivo. No es por tanto una medida incondicional. Junto a estas tres características estructurales básicas de las RB, Iglesias (2003 y 2004) añade una serie de características que subrayan el potencial anticapitalista de la RB y que se dirigen a la consecución de una sociedad más justa, no quedándose meramente en la lucha contra la pobreza:

- La cuantía económica no puede ser inferior a la cantidad reconocida del umbral de la pobreza, es decir, según la Unión Europea el 50\% de la renta per cápita de la zona/territorio/comunidad en el que se implante?

- La percepción de la cuantía se establece en dos partes, una parte que se entregaría en mano a la persona y otra que se incluiría dentro de un fondo común, gestionado de forma democrática por todas las personas y dirigido a la financiación y gestión de los bienes y servicios públicos.

- La RB implica una progresiva refundición de la mayoría de las prestaciones económicas del Estado de Bienestar, con la intención de que toda la ciudadanía disfrute de forma equitativa de este derecho.

- Participación directa e impulso desde la base social, la movilización e implantación de la RB se realiza desde los propios movimientos sociales.

\section{¿A qué objetivos se dirigen las Rentas Básicas?}

Siguiendo a Lo Vuelo (1995) y a Iglesias Fernández (1998 y 2003), la implantación de las RB favorecería el cumplimiento de una serie de objetivos, entre los cuales destaco los siguientes:

- Una mejor redistribución de la riqueza y una erradicación de la pobreza, al menos de las situaciones cuyas causas sean la falta de ingresos económicos y las dificultades originadas en la relación del sujeto con el mercado de trabajo asalariado.

- Se favorecería la reducción de los costos administrativos y burocráticos. Lo cual redundaría en un menor control social por parte de las administraciones públicas en la ciudadanía ${ }^{10}$. Asimismo, mediante el carácter universal de las RB desaparecería la estigmatización social generada por diversos subsidios asistenciales que focalizan su actuación en colectivos determinados como las prestaciones económicas por desempleo, pobreza o jubilación.

- El marco en el que se integran las RB da lugar a una potenciación de mecanismos de participación ciudadana, pero no a través de los procedimientos representativos de las democracias formales, sino mediante prácticas de participación directa de la ciudadanía en los asuntos de la comunidad en la que viven.

- Una transformación profunda del mercado de trabajo en donde, al desvincular los derechos de ciudadanía con la obligación del paso por el mercado de trabajo asalariado, se mejorarían las condiciones laborales. El trabajador fortalecería su posición en el mercado laboral, ya que no estaría obligado a aceptar las condiciones laborales impuestas y por ello, ganaría poder de negociación.

- Por último, la RB contribuiría a crear una mayor seguridad individual en el sujeto, al garantizar una estabilidad -un colchón económico- que le permitiera iniciar proyectos vitales

\footnotetext{
9 Por ejemplo, en un reciente estudio (2011) sobre la viabilidad económica y social de la RB en el municipio canario de La Orotava (España), tal cuantía económica sería de 828 euros mensuales para toda la población. ${ }^{10}$ Evitándose de esta manera la violencia simbólica que el Estado ejerce sobre las personas, en forma de intrusión en su vida personal y/o de humillación (Sanzo González, 2005, p. 135).
} 
y nuevos estilos de vida sin temor a las eventuales contingencias del mercado laboral: desempleo, enfermedad, ancianidad o precariedad.

Las RB por su carácter global se puede considerar que contribuyen a aglutinar en su seno a diferentes movimientos y planteamientos críticos con el sistema capitalista (Iglesias Fernández, 1998). Diversos movimientos sociales, como entre otros el ecologismo, el feminismo, las teorías del decrecimiento, el pacifismo, etc.

\section{Algunas cuestiones referentes a la viabilidad y/o deseabilidad de la propuesta de las Rentas Básicas}

La viabilidad y la pertinencia de esta propuesta únicamente puede venir fruto de un proceso social de base de carácter democrático y no a través de informes técnicos promovidos por instituciones académicas o científicas, o impulsado por directrices políticas. Siguiendo a Raventós (1999) las principales críticas a esta medida se pueden agrupar en dos grandes bloques:

Críticas económicas: Serían aquellas que se dirigen al cuestionamiento de la viabilidad económica de esta propuesta, al aducir que no existe riqueza/dinero bastante para desarrollar esta propuesta. Son críticas que se suelen presentar así mismas como técnicas, neutrales y aideológicas ${ }^{11}$.

En primer lugar, señalar que la RB se aplica sobre el nivel de riqueza ya creado, es decir, no implica la necesidad de un aumento del Producto Interior Bruto (PIB), ni un aumento de la productividad. La RB se dirige a una redistribución de la riqueza ya existente. En nuestras sociedades cada vez se produce más y más riqueza, pero su distribución cada vez está más restringida entre unos pocos. Un par de ejemplos serán suficientes: en el año 2000 los altos directivos de una empresa en USA ganaban 419 veces más que los trabajadores manuales, mientras que esa diferencia en 1990 era de 42 veces (Wacquant, 2000, p. 78). En el periodo entre 1994 y 1998 las 200 personas más ricas del mundo duplicaron su riqueza a 1042 millones de dólares, cifra similar a la renta del $41 \%$ de la población mundial (Callinicos, 2003, p. 11). El problema por tanto no es de falta de riqueza o de producción, sino de la escandalosa falta de reparto de la misma. En este sentido, la RB pone el acento en el carácter colectivo de la producción de valor, de riqueza, de conocimiento, etc. Señalando por un lado, la imposibilidad de desligar el carácter individual del social en toda producción y por otro, al poner sobre la mesa el reconocimiento de la importancia del esfuerzo de las generaciones pasadas ${ }^{12}$.

En segundo lugar, existen diferentes estudios y propuestas sobre la viabilidad económica de la RB en diferentes países (Raventós Pañella, 2001, Iglesias Fernández, 2003, Raventós Panella y Wark, 2011, etc.). Así como diferentes fórmulas y procedimientos a la hora de financiar esta propuesta, desde una transformación de la estructura impositiva, hasta la refundición de las diversas prestaciones económicas y subsidios que actualmente existen, pasando por la supresión del gasto militar, el establecimiento de nuevas cuotas como una Ecotasa o la Tasa Tobin, etc.

Con relación a las cuestiones sobre la pertinencia ética de la RB: En este bloque se encuadran las críticas que señalan el supuesto carácter desmotivador que la RB tendría hacía el

\footnotetext{
${ }^{11}$ Como si de verdad fuese posible establecer un campo, una posición, una opinión axiológica, exenta de toda ideología. Tal afirmación constituye de por sí una de las formas más básicas y primarias de la ideología, puesto que la ideología nunca dice: soy ideológica" (Althusser, 2004, p. 148).

12 “...es posible justificar la apropiación colectiva de la riqueza basándose precisamente en el carácter global, universal de la producción capitalista. Este carácter global, universal de la producción hace que no se puedan individualizar las aportaciones concretas que cada trabajador hace a la creación de riqueza en su conjunto y debilita las justificaciones de corte meritocrático que discriminan entre las diversas aportaciones."(Martínez, 1998, p. 6).
} 
trabajo y cómo esta propuesta acabaría favoreciendo la pereza y el parasitismo social. Bajo esta crítica se esconde una concepción reduccionista del trabajo, por la cual el único trabajo válido sería el asalariado y sancionado dentro de las reglas capitalistas, quedando otros tipos de trabajo (voluntariado, cuidados personales y familiares, diferentes formas de trabajo creativo, artístico, etc.) en un segundo plano a pesar de su carácter imprescindible para la vida humana. La RB critica el carácter explotador que tiene el trabajo asalariado dentro del marco de relaciones laborales capitalista y cómo éste aliena a la persona y contribuye a reproducir la desigualdad social. Una naturaleza explotadora que actualmente adquiere un carácter mucho más explícito con la explosión de desempleo que ha traído la crisis económica del 2008 y en donde las condiciones laborales se han visto dramáticamente empeoradas en todo el mundo.

Bajo el prisma de las RB, se cuestiona la idea a través de la cual la integración social de la persona se lleva a cabo fundamentalmente a través del trabajo asalariado, de que los derechos de ciudadanía vengan de la mano de la inserción en el mercado de trabajo. La RB propone un modelo de integración social en el que se plantea la existencia de diversos modos de vinculación social y en los que el trabajo asalariado es solamente uno más ${ }^{13}$. En este sentido, se supera el carácter reduccionista del capitalismo para el que el acceso al mercado laboral sancionado por las leyes capitalistas es el mecanismo privilegiado para obtener el derecho al disfrute de la ciudadanía social.

La idea de que la RB fomenta el parasitismo social proviene del discurso neoliberal por el cual se caracteriza la naturaleza esencial del sujeto como la de un ser individualista, egoísta que adquiere su realización personal en la competición -dentro de la lógica del mercado- con otros sujetos y en la posesión y consumo de bienes (Cascante Fernández, 2005 y 2006). Esta concepción del sujeto neoliberalista choca con la visión humanista que propone el discurso social-liberal, por el cual el sujeto es un ser dotado de una naturaleza bondadosa y altruista que adquiere su máximo desarrollo a través de la Educación y de la Razón universal. Ambos discursos se engloban dentro del pensamiento moderno, por el cual existe una naturaleza esencial en el sujeto, naturaleza que puede ser desarrollada en el marco de la lógica del mercado para el enfoque neoliberal, o en el marco de las ciencias, de las artes y del conocimiento, en su faceta social-ilustrada.

${ }^{13}$ Como señala Aguado Abad (2000): "El trabajo asalariado puede convertir a la persona en una buena trabajadora asalariada y en una buena consumista, pero lo que es evidente es que no se puede esperar que el trabajo asalariado enseñe otras cosas, como por ejemplo a ser padre o madre, a ser un amante de las artes y de las letras (...) El error que se comete al afirmar que el trabajo asalariado socializa, queriendo decir que es el principal modo de socialización del individuo, es del mismo tipo que el que se comete cuando se equipara trabajo a trabajo asalariado, un acto, en definitiva, de estrechez de miras por el cual se niega las vidas y las realidades de la mayoría de las personas que forman parte de la sociedad. Se trata de una afirmación que simplifica la realidad social, proporciona una visión simple de la vida, en la que lo relevante es trabajar y consumir y lo demás sólo cobra sentido en cuanto constituye un medio para estos fines.” (p. 27). 
Tabla 1.

Cuadro-resumen Rentas Minimas de Inserción y Rentas Básicas. Elaboración propia

\begin{tabular}{|c|c|c|c|c|c|}
\hline Modelos & $\begin{array}{l}\text { Sociedad } \\
\text { Salarial }\end{array}$ & $\begin{array}{l}\text { Discurso } \\
\text { Ideológico }\end{array}$ & $\begin{array}{l}\text { Ciudadanía } \\
\text { Social y } \\
\text { Derechos. }\end{array}$ & $\begin{array}{l}\text { Exclusión } \\
\text { Social e } \\
\text { Intervención } \\
\text { Social }\end{array}$ & $\begin{array}{l}\text { Participación } \\
\text { Ciudadana }\end{array}$ \\
\hline $\begin{array}{l}\text { Rentas } \\
\text { Mínimas } \\
\text { Inserción }\end{array}$ & $\begin{array}{l}\text { Defensa y } \\
\text { legitimación } \\
\text { de los } \\
\text { principios y } \\
\text { valores de la } \\
\text { Sociedad } \\
\text { salarial. } \\
\text { Aceptándose } \\
\text { la fórmula: } \\
\text { Educación- } \\
\text { Inserción } \\
\text { laboral- } \\
\text { derechos } \\
\text { ciudadanía. }\end{array}$ & $\begin{array}{l}\text { Pensamiento } \\
\text { liberal, bien } \\
\text { en la faceta } \\
\text { social- } \\
\text { ilustrada o en } \\
\text { la neoliberal. }\end{array}$ & $\begin{array}{l}\text { A través de la } \\
\text { inserción } \\
\text { laboral en el } \\
\text { mercado } \\
\text { capitalista el } \\
\text { sujeto obtiene } \\
\text { el acceso a los } \\
\text { derechos de } \\
\text { ciudadanía. }\end{array}$ & $\begin{array}{l}\text { Las RMI son un } \\
\text { instrumento } \\
\text { asistencial de } \\
\text { lucha contra la } \\
\text { pobreza, sin } \\
\text { cuestionar las } \\
\text { raíces en que } \\
\text { ésta se origina. } \\
\text { La pobreza es } \\
\text { un fenómeno } \\
\text { individual, en la } \\
\text { forma de déficits } \\
\text { y fallas del } \\
\text { sujeto, que } \\
\text { eventualmente } \\
\text { pueden ser } \\
\text { agravadas por la } \\
\text { coyuntura } \\
\text { económica. }\end{array}$ & $\begin{array}{l}\text { Participación } \\
\text { de tipo } \\
\text { representativa y } \\
\text { delegada por la } \\
\text { ciudadanía a } \\
\text { unas élites en la } \\
\text { toma de } \\
\text { decisiones. Por } \\
\text { ejemplo: } \\
\text { partidos } \\
\text { políticos, } \\
\text { sindicatos, } \\
\text { asociaciones, } \\
\text { grandes ONGs, } \\
\text { etc. }\end{array}$ \\
\hline $\begin{array}{l}\text { Rentas } \\
\text { Básicas } \\
\text { (Modelo } \\
\text { Anticapital } \\
\text { ista) }\end{array}$ & $\begin{array}{l}\text { Cuestionamie } \\
\text { nto y rechazo } \\
\text { de la Sociedad } \\
\text { salarial, en el } \\
\text { reconocimien } \\
\text { to de que éste } \\
\text { actúa como } \\
\text { un elemento } \\
\text { de opresión } \\
\text { de clase y } \\
\text { reproducción } \\
\text { social. }\end{array}$ & $\begin{array}{l}\text { Pensamiento } \\
\text { (post)marxista } \\
\text { y anarquista } \\
\text { de corte } \\
\text { solidario y } \\
\text { comunitario. } \\
\text { Quedan } \\
\text { excluidas } \\
\text { todas aquellas } \\
\text { versiones } \\
\text { dictatoriales } \\
\text { del marxismo } \\
\text { y las } \\
\text { individualistas } \\
\text { del } \\
\text { anarquismo. }\end{array}$ & $\begin{array}{l}\text { Los derechos } \\
\text { de ciudadanía } \\
\text { se adquieren } \\
\text { por la } \\
\text { condición de } \\
\text { ciudadano y no } \\
\text { requieren la } \\
\text { necesidad de } \\
\text { ser sancionados } \\
\text { únicamente por } \\
\text { el mercado } \\
\text { asalariado } \\
\text { capitalista. }\end{array}$ & $\begin{array}{l}\text { Las RB se } \\
\text { dirigen a la } \\
\text { transformación } \\
\text { del orden social } \\
\text { y ponen sobre la } \\
\text { mesa el injusto } \\
\text { reparto de la } \\
\text { riqueza. Desde } \\
\text { las RB la } \\
\text { pobreza es una } \\
\text { consecuencia del } \\
\text { injusto sistema } \\
\text { económico y } \\
\text { social que } \\
\text { impone el } \\
\text { capitalismo. }\end{array}$ & $\begin{array}{l}\text { Basada en los } \\
\text { principios de la } \\
\text { acción directa y } \\
\text { de la } \\
\text { democracia } \\
\text { participativa. } \\
\text { Por ejemplo a } \\
\text { través de } \\
\text { cooperativas, } \\
\text { centros sociales } \\
\text { autogestionado } \\
\text { s, etc. }\end{array}$ \\
\hline
\end{tabular}




\section{La acción socioeducativa desde estas dos perspectivas: ¿Qué relaciones existen entre la Pedagogía social y las Rentas Mínimas de Inserción y las Rentas \\ Básicas?}

Hemos visto en las líneas anteriores que las RMI y las RB en su versión fuerte conllevan formas muy distintas de ver y entender la realidad social en aspectos como intervención social, participación de la ciudadanía, bases ideológicas, etc. Por tanto, las propuestas de acción socioeducativa que emanen de ellas serán por fuerza muy diferentes también. Teniendo en cuenta la complejidad y amplitud de este apartado, me voy a centrar en desarrollar dos dimensiones de la pedagogía social, por un lado la Educación de adultos y por otro la Participación ciudadana, en su relación con estas dos propuestas de carácter antagónico.

La acción educativa (en contextos formales y no formales) y su relación con las Rentas Mínimas de Inserción y las Rentas Básicas

Para explorar las relaciones existentes entre la acción educativa en un sentido amplio, dentro de las RMI y de las RB me basaré en la estrategia metodológica de la triple esfera de las decisiones curriculares (Cascante Fernández, 2005, 2006, 2007, etc.). ${ }^{14}$

Tabla 2.

Estrategia analítica para las acciones educativas desde las propuestas de las RMI y de las RB. Elaboración propia

\begin{tabular}{|c|c|}
\hline $\begin{array}{l}\text { Esferas de Toma de Decisiones } \\
\text { Educativas }\end{array}$ & Rentas Mínimas Inserciőn \\
\hline $\begin{array}{l}\text { Decisiones Técnicas } \\
\text { (Responden a la cuestión de } \\
\text { ¿Qué se hace?) }\end{array}$ & $\begin{array}{l}\text { 1. ¿Cómo es el diseño de la acción socioeducativa? } \\
\text { 2. ¿Qué tipo de contenidos educativos se ofrecen? } \\
\text { 3. ¿Qué rol tienen el docente y el discente? } \\
\text { 4. ¿Qué metodologías didácticas o de intervención se } \\
\text { utilizan? } \\
\text { Etc. }\end{array}$ \\
\hline $\begin{array}{l}\text { DECISIONES TEÓRICAS } \\
\text { (Responden a la cuestión de } \\
\text { ¿Por qué se hace?) }\end{array}$ & $\begin{array}{l}\text { 1. ¿Cuál es la relación entre exclusión y formación? } \\
\text { 2. ¿Qué teorías psicológicas sustentan la acción } \\
\text { educativa? } \\
\text { Etc. }\end{array}$ \\
\hline $\begin{array}{l}\text { Decisiones Metateóricas } \\
\text { (Responden a la cuestión de } \\
\text { ¿Para qué se bacen?) }\end{array}$ & $\begin{array}{l}\text { 1. ¿Qué concepto de sujeto se considera? } \\
\text { 2. ¿Qué papel tiene la educación en la sociedad? } \\
\text { 3. ¿Cuál es la relación cognoscitiva entre sujeto y } \\
\text { objeto? ¿Qué es el conocimiento? } \\
\text { Etc. }\end{array}$ \\
\hline
\end{tabular}

Desde esta estrategia analítica se plantea una aproximación progresiva al fenómeno educativa, desde el análisis de las decisiones curriculares que se toman en el contexto más cercano en donde se realiza la acción educativa, lo que serían las decisiones curriculares técnicas. A continuación se analizarían aquellas decisiones curriculares que sustentan teóricamente la acción educativa, las decisiones teóricas; y por último, aquellas decisiones de orden más abstracto y filosófico que son las más

\footnotetext{
${ }^{14}$ En otro trabajo (Rodríguez Fernández, 2011) planteo una aproximación analítica al fenómeno educativo utilizando el marco analítico de la Teoría de los Intereses de Habermas (1981).
} 
alejadas de la práctica, pero que subyacen y configuran toda propuesta socioeducativa, las decisiones metateóricas ${ }^{15}$.

Esta aproximación analítica al fenómeno educativo nos permite analizar los hilos conductores que dotan de coherencia las diferentes dimensiones de toda propuesta educativa. Puesto que las decisiones que se tomen en las diferentes esferas están relacionadas y articuladas en consonancia con los diversos discursos educativos que las nutren.

\section{Las decisiones técnicas, teóricas y meta-teóricas en las propuestas educativas en las Rentas Mínimas de Inserción}

Las acciones educativas desde las RMI están directamente determinadas por un énfasis en la centralidad del trabajo y en la inserción laboral de las personas beneficiarias de estas prestaciones. La formación dentro de los programas de RMI se desarrolla bajo el discurso de la empleabilidady de la activación laboral de las personas en exclusión social. Ante este objetivo, los contenidos de la acción educativa se limitan a aquellos directamente vinculados con las necesidades del sistema productivo, asumiendo la forma de contenidos teóricos y/o de técnicas laborales. Contenidos educativos típicos dentro de estos programas de RMI son aquellos que inciden en las habilidades pre-labórales o laborales específicas, por ejemplo: habilidades sociales, autoestima, elaboración de curriculums vitae, jardinería, mecánica, hostelería, lavandería, etc.

La conformación de los contenidos educativos está así determinada de antemano y se relaciona directamente con metodologías didácticas de corte transmisivo, expositivo y que subrayen la práctica lineal de lo aprendido. Aquí es donde aparece el auge de las llamadas metodologías por competencias, las cuales resultan especialmente funcionales para el mundo de la empresa. Desde esta visión, los roles del docente/educador y del alumnado están bien delimitados, correspondiéndole al primero el ser un transmisor, lo más preciso posible, del conocimiento y al segundo, el ser un receptor pasivo del mismo.

Bajo esta concepción, el diseño de las acciones educativas en sus diferentes dimensiones: contenidos, acciones, objetivos, actividades, etc. es una tarea que corresponde a los profesionales o a los técnicos expertos. Siendo el alumnado, y en muchas ocasiones el propio profesorado meros agentes encargados de llevar a la práctica lo diseñado de forma externa a ellos. Por ello, se expropia de su labor cualquier tipo de reflexión y reelaboración sobre sus prácticas y sobre la naturaleza de la acción socioeducativa.

Las teorías psicológicas del aprendizaje que sustentan estos posicionamientos educativos son aquellas que enfatizan la separación entre sujeto y objeto de conocimiento. Es decir las teorías externalistas como por ejemplo diversas formas del conductismo y del aprendizaje social, y las teorías mediacionales como el proceso-producto, el aprendizaje significativo, etc. que incorporan algún tipo de importancia al papel mediador de la estructura cognitiva, pero sin romper con la dicotomía sujeto-objeto (Cascante, 2002).

En un plano más general, en este discurso de la empleabilidad, la formación es vista de doble manera: Primero, como un elemento central dentro de la inserción sociolaboral del sujeto. Se entiende que la exclusión social es fruto de los déficits y de las fallas formativas-personales del sujeto -déficits que pueden agravarse con las diversas contingencias del mercado- y que es la ausencia de las credenciales formativas adecuadas la raíz de su situación de exclusión social. Y segundo, la formación es la redención de la persona pobre, es decir, es el peaje y el castigo que el pobre tiene que pasar para poder acceder de forma legítima a la beneficencia pública y a la caridad social.

\footnotetext{
${ }^{15}$ No olvidemos, siguiendo a Freire (1971), que toda propuesta educativa implica una concepción de hombre y de mundo.
} 
Por último en el plano más global y más abstracto, el discurso de la empleabilidad en las acciones formativas de las RMI participa de la idea liberal por la cual la educación se sitúa en el centro de la trama social, como motor del desarrollo y progreso de la sociedad. Partiendo de esta idea, la educación es la responsable en buena parte de los problemas sociales, por ejemplo del desempleo puesto que se la acusa de no formar adecuadamente para el trabajo, o de no abrirse totalmente a la participación privada de la empresa. A su vez para el pensamiento liberal, la educación aparece como la garante de la igualdad de oportunidades y el artífice de la movilidad social. Si se acepta el supuesto neoliberal, por el que el mercado y la libertad individual garantizan la igualdad de oportunidades para el sujeto, entonces la educación se configura como el campo en el que el esfuerzo y la iniciativa individual del sujeto, le permitirá avanzar y lograr sus metas sociales en la competición que ofrece la autopista del conocimiento.

La concepción de sujeto, como hemos visto anteriormente, es la del sujeto individualista, competitivo y calculador, que mediante inversiones personales en educación y en otros capitales simbólicos compite en el mercado con otros sujetos. Todo ello con el objetivo central de la inserción en el mundo laboral y en el mundo del consumo, siendo el logro de estos objetivos donde el sujeto neoliberal desarrolla plenamente su naturaleza esencial. Es el discurso del sujeto emprendedor, el paradigma neoliberal del éxito social.

\section{Las decisiones técnicas, teóricas y metateóricas en las propuestas formativas relacionadas con las Rentas Básicas}

El horizonte que se dibuja para la educación y la formación en las RB es muy diferente del imaginario establecido por las RMI, situándose dentro de los márgenes de la pedagogía crítica y transformadora. La acción educativa se desvincula, desde el prisma de las RB, de los principios del Capital Humano (Becker, 1983) que señalan que la educación es una inversión personal mediante la cual el sujeto adquiere las competencias necesarias para insertarse en el mercado laboral. La educación desde esta óptica neoliberal se convierte en un subsistema del aparato productivo, cuya función es la de suministrar pasivamente las competencias que éste necesite ante los constantes cambios en las necesidades productivas. La educación como capital humano se relaciona íntimamente con la idea del aprendizaje para toda la vida (Life-long learning) y con la progresiva penetración de empresas privadas dedicadas a cubrir estas necesidades laborales, en el denominado negocio de la formación ${ }^{16}$.

Bajo esta perspectiva, la educación se convierte en una mercancía más sujeta a las leyes de la oferta y de la demanda. Una mercancía que se entiende como un producto más dentro de la sociedad del consumo (Bauman, 2007), una opción personal de consumo y no como un derecho público de ciudadanía. Como señala Gentili (1997): "La reforma administrativa propuesta por el neoliberalismo se orienta a desmantelar la educación, a transferirla a la esfera de la competencia privada. Reducida a su condición de mercancía, la educación sólo debe ser protegida no por supuestos derechos sociales, sino por los derechos que asisten el uso y disposición de la propiedad privada por parte de sus legítimos propietarios. Es en este marco en el que se reconceptualiza la noción de ciudadanía mediante una revalorización de la acción del individuo en cuanto propietario que elige, opta, compite para acceder (comprar) un conjunto de propiedades-mercancías de diversa índole, siendo la educación una de ellas. El modelo de hombre neoliberal es el ciudadano privatizado, responsable, dinámico: el consumidor' (p. 60).

\footnotetext{
${ }^{16}$ En donde se considera que la Educación puede representar un volumen de negocio incluso superior al de la industria del automóvil (Fernández Rodríguez, 2009, p. 157). Negocio al que acuden presto diversos organismos públicos, privados, sindicatos y organizaciones políticas, empresas de formación online, universidades, ONGs, etc.
} 
Asimismo, la acción educativa en las RB tampoco se entiende como un producto final fruto del avance de las ciencias y de las artes. Un producto que debe ser transmitido por la Escuela y que representa la expresión más alta de la racionalidad y de los valores éticos y morales de la Ilustración. Ante esta visión humanista y siguiendo los principios de la pedagogía crítica, se considera que los contenidos curriculares no dejan un resultado de relaciones asimétricas de poder y una imposición de las clases superiores por las cuales legitiman su cultura, y que por lo tanto deben ser confrontados y cuestionados ${ }^{17}$.

En ambos discursos la educación se configura bajo la idea de una educación bancaria (Freire, 1971), en la cual el docente deposita unos contenidos, que pueden adoptar la forma de técnicas y competencias profesionales y/o la de conocimientos culturales, académicos, artísticos... en la mente de los sujetos. Sujetos discentes que a modo de recipientes vacíos deben ser llenados con los productos elaborados por las diferentes disciplinas científicas. En un proceso en el cual el rol del alumnado es meramente pasivo y el del docente el de un intermediario, un tendero del saber. En última instancia estos discursos educativos de corte liberal contribuyen a la reproducción y al mantenimiento del orden social existente.

La concepción educativa en las RB se aleja del horizonte dibujado por estos discursos educativos liberales: tanto del que afirma la dependencia lineal con el sistema productivo, como del discurso social-liberal por el cual la educación debe ser una transmisión de la cultural elevada y de los valores del proyecto de la Ilustración. La concepción educativa en las RB se relaciona con el cuestionamiento y la reflexión crítica sobre orden social y sobre las instituciones sociales y sus fines, todo ello con la intención de contribuir a la construcción de una sociedad más justa e igualitaria.

La educación de adultos se dirige a la problematización y a la toma de conciencia social sobre los problemas del mundo, para lo cual es necesario introducir contenidos curriculares y prácticas contrahegemónicas que contribuyan a descubrir las situaciones de injusticia social. De esta forma se rompe tanto con la idea ilustrada que afirma que toda educación es buena per se ${ }^{18}$; y con la idea neoliberal que reduce la educación a la consecución de competencias profesionales con las cuales el sujeto después competirá con otros sujetos por la obtención de un puesto de trabajo en el mercado laboral.

La educación desde este prisma contrahegemónico, debe incidir en la reflexión conjunta y en el diálogo entre todos los participantes, por ello se relaciona estrechamente con planteamientos que hagan hincapié en el funcionamiento democrático, en la autogestión, en la construcción conjunta del conocimiento, en la ruptura de las barreras disciplinares y curriculares, en la difuminación de las jerarquías docente/alumno, en el aprendizaje cooperativo y dialógico, etc. En esta línea, se sitúan prácticas educativas como las comunidades de aprendizaje de personas adultas (Flecha, 1990), los procedimientos de Investigación-Acción en sus tradiciones crítica (Carr y Kemmis, 1988) y participativa de Orlando Fals Borda (Salazar, 1992) o las propuestas de currículum integrado como la Transversalidad de los contenidos, los Centros de interés y especialmente por su carácter sociopolítico, la enseñanza dialógica en las campañas de alfabetización de Freire (1971). Se trata de metodologías educativas que se abren a la consideración del papel que las estructuras sociales tienen en el proceso educativo y en el desarrollo psicológico de los sujetos.

\footnotetext{
${ }^{17}$ Como comenta Silva (2001) con relación al curriculum universitario tradicional: “...veían ese canon como la expresión del privilegio de la cultura blanca, masculina, europea, heterosexual. El canon del currículum universitario hacía pasar por 'cultura común' una cultura bastante particular: la cultura del grupo cultural y socialmente dominante.” (p. 107).

${ }^{18}$ Desde la sociología crítica de la educación (Lerena Alesón (1983), Bourdieu y Passeron (1985), Bowles y Gintis (1985), Willis (1988), Torres (1994), etc.) se afirma que la educación si no tiene un componente de problematización, de práctica contrahegemónica, no es liberalizadora en absoluto, contribuyendo a la reproducción y mantenimiento del status quo.
} 
En estas metodologías didácticas, se difumina la fractura entre el técnico experto y el alumnado, convirtiéndose todos los agentes educativos en sujetos activos de aprendizaje. El educador no es ya un experto en técnicas, sino un docente reflexivo (Schön, 1992), que implicado con el grupo y la comunidad donde desarrolla su acción, fomenta el desarrollo de prácticas de concienciación social y la introducción de contenidos socialmente relevantes que problematicen la realidad de la comunidad. En esta perspectiva, el papel del alumnado no puede ser el de receptor pasivo, sino que tiene un rol protagonista en la (re)elaboración de los contenidos, en la determinación de las prácticas, etc. es decir, es un sujeto activo en el diálogo socioeducativo.

El saber educativo se conceptualiza de forma diferente a como veíamos anteriormente, apareciendo como fruto del debate y la reflexión de la comunidad educativa y no como un paquete de contenidos ajeno al sujeto que siguiendo el símil informático hubiese que descargar en la memoria de los educandos. Por ello, cualquier tipo de diseño, de planificación socioeducativa debe emerger de un proceso que contemple la participación directa de las bases sociales donde se vaya a realizar. La acción educativa, adopte la forma que adopte, no puede ser una prescripción técnica elaborada por expertos desde fuera de la comunidad donde se quiera aplicar, sino que tiene que estar firmemente enraizada en las bases. En otros términos, la cuestión es devolver la voz y la palabra al pueblo (Freire, 1971) asumiendo que la acción educativa crítica conlleva un posicionamiento ético-político a favor de los colectivos en desventaja social ${ }^{19}$.

Desde una perspectiva más amplia, las RB al plantear el carácter opresor de los principios de la sociedad salarial, rompen con la centralidad de la empleabilidad y con la supeditación de la educación a los intereses de la empresa. Esta negación no excluye que la educación deba tener algún tipo de relación con el trabajo, pero sí que niega su subordinación lineal ante las demandas del mundo empresarial. Partiendo de esta base, desde la acción socioeducativa se vuelve imprescindible el abordar reflexivamente la precariedad a la que nos aboca el mercado laboral y las diversas reformas legislativas que sobre los mercados laborales se están llevando a cabo, reformas encaminadas a aumentar la flexibilidad de las condiciones laborales del trabajador. Tampoco puede quedar fuera la consideración de los efectos sociales, económicos y medioambientales que tiene el trabajo, es decir, desde la educación se tiene que abordar la formación para el empleo mediante una óptica interdisciplinar y transversal que tenga en cuenta estos aspectos. Y no únicamente una formación para la adquisición de competencias profesionales.

La concepción de sujeto que se defiende desde las propuestas socioeducativas relacionadas con las RB, se aleja también de la representada por el discurso neoliberal de las RMI. El sujeto pasa a ser visto como un ser social que no se rige sólo por los principios racionales de coste-beneficio, sino fundamentalmente por los principios de solidaridad y apoyo mutuo. Este sujeto adquiere y ejerce su libertad en las prácticas que posibilitan la libertad de los otros, en oposición a la concepción negativa de libertad por la cual la libertad del sujeto es limitada por la libertad de otros sujetos en la competición que tiene lugar en la arena del mercado social.

\section{Participación social ciudadana}

En el pensamiento liberal la participación democrática del ciudadano se desarrolla a través de instituciones/organizaciones basadas en el principio de representatividad (por ejemplo los partidos políticos) y en asociaciones que representen los intereses individuales y/o colectivos, como por ejemplo los colegios profesionales, o las diferentes asociaciones que integran la sociedad liberal civil. Estas instituciones se entienden como productos que dentro del mercado, son elegidos por el

${ }^{19}$ Como afirma Zinn (1997) el grito de los oprimidos no siempre es justo, pero si no lo escuchas, nunca sabrás qué es la justicia. 
ciudadano-consumidor según sus intereses y sus necesidades. La participación se limita a la capacidad de elección del individuo entre la oferta de productos que proporcione el mercado.

A través de estos procedimientos de participación, la ciudadanía delega -habitualmente a través de procesos electorales- en unas élites la toma de decisiones políticas durante un periodo de tiempo determinado. Actualmente, existe un creciente desprestigio de estos procedimientos democráticos formales en relación a su capacidad para representar los intereses de la ciudadanía popular y de su capacidad para romper con las ataduras que tienen con los poderes burocráticos económicos privados. Este desprestigio da lugar a que en los procesos electorales de democracia formal, los niveles de participación sean cada vez menores y la abstención cada vez mayor.

La participación ciudadana desde las RB incide en la necesidad de potenciar los mecanismos que propicien la participación directa de las propias personas en los asuntos que les involucren. Asumiendo por ello los principios herederos de la tradición libertaria-solidaria de la autogestión, del asamblearismo y de la participación directa de la ciudadanía (Chomsky, 2008). Dentro de este planteamiento se integran prácticas que tratan de profundizar la democracia en su vertiente más participativa, como por ejemplo:

- Estudios de viabilidad de las RB: En donde no se trata de estudios técnicos realizados por expertos externos, en la forma de informes técnicos académicos o de prescripciones realizadas por fundaciones privadas. Sino que consisten en pretextos para la reflexión conjunta sobre la realidad de nuestras ciudades, barrios, etc. En estos estudios es habitual la realización de dinámicas de grupo, técnicas de dinamización social, grupos de debate, entrevistas en profundidad, etc. Son estudios cuyo diseño y sentido viene a ser muy similar a los ciclos clásicos de los procesos de investigación-acción de planificación, acción, observación y reflexión. Sus objetivos, por tanto, se dirigen a fomentar la participación popular, la reflexión, el debate, el diálogo y la reelaboración de ideas; más que a dar respuestas, al diagnóstico y/o a la prescripción técnica.

- Presupuestos participativos: Las RB en su versión anticapitalista incluyen la creación de un fondo económico común con el que financiar los diversos servicios públicos de la comunidad (sanidad, educación, transporte, etc.). Este fondo comunitario es gestionado de forma directa, por los propios integrantes de la comunidad, al igual que ocurre con la herramienta de los presupuestos participativos. Herramienta puesta en marcha originalmente en 1989 en Porto Alegre y que desde entonces ha sido desarrollada en diversas ciudades del mundo, tanto en el contexto de América Latina, como en Europa (Díez Gutiérrez, 2007). A través de los presupuestos participativos se fomenta el desarrollo de una conciencia de ciudadanía y de una cultura política más deliberativa, educativa y democrática (Lerner y Schugurensky, 2007). Asimismo, desde esta perspectiva se redefine lo "público" como un espacio de todos y para todos y no meramente como un espacio gestionado por las administraciones públicas, como desde las visiones estatistas se plantea. Por ello, entiendo que los presupuestos participativos constituyen una herramienta absolutamente compatible con los principios en los que se asienta la RB en la interpretación que defiendo en estas líneas.

- Centros sociales comunitarios, radios libres, bibliotecas de barrio, oficinas de información social, charlasdebates, ciclos de cine, etc: Todas ellas experiencias basadas en la creación de comunidades autónomas y orientadas por el trabajo cooperativo, el apoyo mutuo y la autogestión. Se trata de prácticas de participación que inciden en la dimensión comunitaria, en lo público, a diferencia de aquellas actuaciones orientadas por una lógica empresarial de beneficio privado. En definitiva, la RB se orienta a la regeneración de los espacios públicos y al fomento de la solidaridad social, frente a las medidas que buscan la privatización de los espacios urbanos y la orientación de su uso a la lógica de la búsqueda de rendimiento económico privado. Como ocurre 
con las grandes superficies comerciales, que en contextos urbanos han pasado a erigirse como el lugar por excelencia donde las personas disfrutan de su ocio y tiempo libre.

Las RB se relacionan con planteamientos y estrategias que favorecen el desarrollo de una participación de la ciudadanía orientada al análisis crítico de la realidad social, a la movilización social y a la búsqueda de una mayor justicia social a través de procesos iniciados desde la propia base social ciudadana. Este tipo de participación entronca con los principios de la libertad positiva, frente a la libertad negativa que se ejercita en el seno del mercado y que es predominante en las tradiciones del pensamiento liberal.

\section{Conclusiones}

El EB aparece hoy en día en una encrucijada conformada por la crisis del sistema capitalista neoliberal y por el conflicto entre diversos discursos ideológicos que pugnan por la hegemonía. De esta encrucijada surgen tres caminos, a mi modo de ver dos bastante relacionados y un tercero en discordia de carácter más independiente:

Una primera vía, que siguiendo los preceptos del orden neoliberal abogaría por (Navarro, 2007) reducir o reformar las funciones públicas de los EB a favor del libre mercado y privatizar -allí donde fuese rentable- sus diversos servicios ${ }^{20}$. Una segunda línea, que se dirigiría al desarrollo de políticas públicas de creación de pleno empleo, basadas en una fuerte intervención estatal en la regulación de la economía a través de los EB. Esta es la visión sostenida por los planteamientos socialdemócratas más consecuentes y orientados a la izquierda, así como por aquellos que no cuestionan de manera radical el capitalismo actual.

Estas dos caras del pensamiento liberal, la neoliberal y la social-liberal, son las visiones hegemónicas en torno a las cuales se produce el debate social y económico. Y es a la luz de esta relación donde se deben entender las transformaciones que sufre el EB, la dirección que toman las políticas sociales y las medidas y actuaciones vinculadas a ellas: privatización de los servicios públicos (educación, sanidad, servicios sociales...), aumento de la responsabilidad individual, endurecimiento en el acceso a las ayudas y vinculación de las mismas hacia la inserción laboral (workfare) y tratamiento punitivo de la pobreza (Wacquant, 2010).

De forma divergente, cabría establecer aquellas posiciones que critican radicalmente el sistema capitalista, que entienden el EB como un elemento inseparable del mismo y por lo tanto sujeto a sus mismas limitaciones y contradicciones. En este discurso el problema implicaría la construcción de un nuevo proyecto político-social, digamos que una salida por la iqquierda del EB. Creo que la propuesta de las RB en su vertiente anticapitalista se puede ubicar dentro de esta perspectiva. Una propuesta cuya viabilidad técnica se ha demostrado en diferentes estudios y en donde opino que las dudas sobre su viabilidad son más bien una forma de cortina de bumo, cuyo fin es trasladar el debate democrático sobre la pertinencia social e ideológica de esta medida al plano supuestamente técnico, neutral y externo de los expertos. A fin de cuentas, tan imposible no debe ser cuando los gobiernos de los países Occidentales no han dudado en dar ingentes cantidades de dinero público a las entidades financieras privadas, sin mayores problemas y sin prácticamente

\footnotetext{
${ }^{20}$ Como he planteado a lo largo de este texto, quiero dejar claro que no defiendo ni la eliminación, ni la privatización de las instituciones públicas de los EB tal y como plantean los discursos neoliberales en favor de las lógicas del mercado. Las políticas neoliberales han acelerado aún más los efectos de la crisis capitalista (masivos niveles de desempleo, precariedad laboral, pobreza, fragmentación y polarización social...), han empeorado las condiciones laborales del trabajador generalizando un modelo laboral draconiano de o lo tomas o lo dejas y, en definitiva, nos abocan a un mundo más injusto y desigual.
} 
contraprestaciones $^{21}$. Por tanto se puede decir, sarcásticamente, que la banca privada ha tenido su propia renta básica.

Estos tres discursos sobre los EB y sobre las políticas sociales conllevan dentro de sí concepciones diferentes acerca de la Sociedad, del Sujeto, de la Historia, de la Participación, de la Educación, de la Ciudadanía, etc. y por ello, configuran horizontes diferentes para la Pedagogía Social. En este texto he propuesto una metodología analítica, la triple esfera de decisiones-técnicas, teóricas y metateóricas-, que nos permita analizar diferencias en las propuestas socioeducativas relacionadas con las RMI o con el planteamiento de las RB. Esta estrategia analítica nos facilita poder aproximarnos a las relaciones existentes en las diferentes dimensiones según su grado de concreción (metodologías, diseño acciones, rol docente, etc.) de toda propuesta educativa y ver a su vez el hilo de coherencia que las atraviesa. De cara a la formación de profesorado, considero que esta estrategia analítica nos permite a los profesionales de la educación poder reflexionar sobre nuestras prácticas docentes de una manera integrada, de modo que podamos tanto mejorar nuestra labor como desarrollar nuevas prácticas de carácter crítico y emancipatorio, al integrar aspectos de carácter más general y global que habitualmente sobrepasan las fronteras de la práctica diaria en el aula.

Una Pedagogía social crítica y comprometida con la lucha por una sociedad más justa creo que debe tratar de seguir una senda diferente a la trazada por los cauces del caduco pensamiento liberal. Una senda en la que la educación social sea un instrumento más dentro de una estrategia más amplia de acción social revolucionaria y contrahegemónica. En este sentido, este trabajo muestra dos rutas "alternativas" para una pedagogía social transformadora en el siglo XXI, rutas vinculadas al marco que ofrece la propuesta sociopolítica de las RB: Por un lado, en cuanto a principios de procedimiento para las acciones formativas de ámbito formal y no formal para las personas en situación de riesgo social; y por otro, en cuanto a estrategias de participación social ciudadana que apoyándose en los principios de autogestión y de participación directa, ahonden en la práctica de la democracia.

\section{Bibliografía}

Aguado Abad, J. (2000). ¿Por qué decir no a la Renta Básica? Notas para superar las resistencias morales e ideológicas. Curso de Iniciación sobre la Renta Básica. Mota del Cuervo, Madrid.

Aguado Abad, J. (2002). La renta básica y el sistema patriarcal. Cuadernos de Renta Básica, 4.

Althusser, L. Ideología y Aparatos ideológicos del Estado. En Zizek, S. (2004). (Comp.). Ideología. Un mapa de la cuestión. Buenos Aires: Fondo de Cultura Económica.

Amin, S. (2009) La crisis. Salir de la crisis del capitalismo o salir del capitalismo en crisis. Barcelona: El viejo topo.

Arriba González de Durana, A. (2007). La última red de protección social en España: prestaciones asistenciales y su activación. Política y Sociedad, 44(2), 115-133.

Arriba González de Durana, A., Parrilla Fernández, J. M. y Pérez Eransus, B. (2009). Transformaciones de las políticas autonómicas de inclusión social. I Congreso Anual REPS. Oviedo (España), 5-7 de noviembre.

Bauman, Z. (2007). Vida de consumo. Madrid: Fondo de Cultura Económica. Becker, G. (1983). El capital humano. Madrid: Alianza.

\footnotetext{
${ }^{21}$ Se calcula que las aportaciones económicas de los gobiernos para reflotar las entidades bancarias han costado 20 veces más que lo necesario para realizar los Objetivos del Milenio (Díez Gutiérrez, 2009, p. 58).
} 
Bourdieu, P. y Passeron, J. C. (1985). La reproducción. Elementos para una teoría del sistema de enseñanza. Madrid: Popular.

Bourdieu, P. (2000). Contrafuegos. Reflexiones para servir a la resistencia contra la invasión neoliberal. Barcelona. Anagrama.

Bowles, P. y Gintis, S. (1985). La instrucción escolar en la América capitalista. Madrid: Siglo XXI.

Callinicos, A. (2002). Contra la Tercera vía. Madrid: Crítica.

Callinicos, A. (2003). Igualdad. Madrid: Siglo XXI.

Carr, W. y Kemmis, S. (1988). Teoría crítica de la enseñanqa. La investigación acción en la formación del profesorado. Barcelona: Martínez Roca.

Cascante Fernández, C. (2002). La comunicación didáctica y las nuevas tecnologías. III Encuentro Iberoamericano de Economía Política. Sevilla (España).

Cascante Fernández, C. (2005). ¿Cómo puede la educación contribuir a la construcción de identidad, igualdad y justicia social? Encuentro Internacional de educación. Gravatai (Brasil).

Cascante Fernández, C. (2006). ¿Qué hacemos con la educación para construir una ciudadanía multicultural? V Encuentro Internacional Forum Paulo Freire. Valencia (España), 12 al 15 de Septiembre.

Cascante Fernández, C. (2007). ¿Es posible construir otra escuela para una sociedad tecnológica y globalizada alternativa? Cooperación Educativa, 82-83, 7-13.

Cascante Fernández, C. (2008). ¿Cómo podemos desde la educación contribuir a la igualdad y a la justicia? Aula Libre, 86, 27-30.

Chomsky, N. (2007). Crisis inminentes: el legado del neoliberalismo. En Chomsky, N., Cypher, J., Foster, J., Hart-Landsberg, M., Herrera, R., Navarro, V. y Vogel, R. (2007). 25 años de neoliberalismo. Barcelona: Hacer.

Chomsky, N. (2008). Sobre el anarquismo. Pamplona: Laetoli.

Díez Gutiérrez, E. J. (2007). La globalización neoliberal y sus repercusiones en la educación. Barcelona: El Roure.

Díez Gutiérrez, E. J. (2009). Crisis y depresión del capitalismo. Utopías. Nuestra Bandera, 222 (4), 51-63.

Editorial (2013/1/25) Depresión profunda. El País.

Etxezarreta, M., Idoate, E., Iglesias Fernández, J. y Junyent Tarrida, J (2010). Qué pensiones, qué futuro: El Estado de Bienestar en el siglo XXI. Barcelona: Icaria.

Salazar, M. C. (Ed.) (1992). La investigación-acción participativa: Inicios y desarrollos. Madrid: Popular Flecha, R. (1990). Educación de las personas adultas. Propuestas para los noventa. Barcelona: Roure.

Fernández Rodríguez, E. (2009). El discurso de la formación basada en competencias profesionales. Un análisis crítico de la formación inicial de profesionales en la Educación Superior. Revista Electrónica Interuniversitaria de Formación del Profesorado, 12 (1), 151-160. Disponible en www.aufop.com/aufop/uploaded files/articulos/1240873240.pdf.

Foucault, M. (1979). Vigilary castigar. Nacimiento de la prisión. Madrid: Siglo XXI.

Foucault, M. (2003). Hay que defender la sociedad. Madrid: Akal.

Foucault, M. (2008). Seguridad Territorio Población. Madrid: Akal.

Freire, P. (1971). Pedagogía del Oprimido. Madrid: Siglo XXI.

García Escamilla, E. y Sáez Bayona, M. (Coords.).(2010). Vivir donde quieras. Estudio sobre la viabilidad social y económica de la Renta Básica de las Iguales en el municipio de Alfafar (País Valencia). Málaga: Zambra.

Gentili, P. (1997). El consenso de Washington y la crisis de la educación en América Latina. Archipiélago. Cuadernos de crítica de la cultura, 29, 56-66.

Habermas, J. (1981). Conocimiento e interés. Madrid: Taurus. 
Iglesias Fernández, J. (1998). El derecho ciudadano a la renta básica. Economía crítica del bienestar social. Madrid: Los libros de la Catarata.

Iglesias Fernández, J. (2003). Las Rentas Básicas. El modelo fuerte de implantación territorial. Barcelona: El viejo Topo.

Iglesias Fernández, J. (2004). La cultura de las Rentas Básicas. Historia de un concepto. Barcelona: Virus.

Iglesias Fernández, J. (2010). Sobre el decrecimiento y otras rendiciones. Interpretación crítica sobre el decrecimiento y el consumo responsable. Málaga: Zambra.

Isuali, E., Lo Vuolo, R: y Tenti Fanfani, E. (1991). El Estado Benefactor. Un paradigma en crisis. Buenos Aires: Miño y Dávila/CIEPP.

Krugman, P. (2012). Desdén por los trabajadores. El País. 24/09/2012.

Lerena Alesón, C. (1983). Reprimir y liberar: crítica sociológica de la educación y de la cultura contemporáneas. Madrid: Akal.

Lerner, J. y Schugurensky, D. (2007). La dimensión educativa de la democracia local: el caso del presupuesto participativo. Temas y debates, 13, 157-179.

Lo Vuolo, R. (1995). Contra la exclusión. La propuesta del ingreso ciudadano. Buenos Aires: Miño y Dávila.

Lo Vuolo, R. y Raventós Pañella, D. (2009). Basic Income: good in the boom, essential in the crisis. Online opinion. Australia's e-journal of social and political debate. Disponible en: http:/ / www.onlineopinion.com.au/view.asp?article=9172\&page=2. Accedido en: Septiembre 2012.

Lo Vuolo, R., Raventós Pañella, D. y Yanes, P. (2010). El Ingreso Ciudadano-Renta Básica ante la crisis económica y los ataques a los derechos sociales y laborales. En www.sinpermiso.net. Consultado en Febrero 2011.

López Trujillo, Z. y Sáez Bayona, M. (Coords.).(2011). Por el derecho a una vida digna. Estudio sobre la viabilidad social y económica de la Renta Básica de las Iguales en el municipio de La Orotava (Archipiélago Canario). Málaga: Zambra.

Martínez, F. J. (1998). Fundamentos de la RB. Hacia un nuevo contrato social. Cuadernos de RB, 0 .

Martínez, F. J. (2002). Mundialización y redistribución: la propuesta de la Renta Básica. Revista Internacional de Filosofía Política, 19, 5-15.

Martínez, F. J. (2002b). Renta Básica y globalización (Entrevista a Ph. Van Parijs). Revista Internacional de Filosofía Política, 19,179-182.

Navarro, V. (2000). Globalización económica, poder politico y Estado del bienestar. Barcelona: Ariel.

Navarro, V. (2002). Bienestar insuficiente, democracia incompleta. Sobre lo que no se habla en nuestro país. Barcelona: Anagrama.

Navarro, V. (2007). La lucha de clases a escala mundial. En Chomsky, N., Cypher, J., Foster, J., Hart-Landsberg, M., Herrera, R., Navarro, V. y Vogel, R. (2007). 25 años de neoliberalismo. Barcelona: Hacer.

Navarro, V., Torres López, J. y Garzón Espinosa, G. (2011). Hay alternativas. Propuestas para crear empleo y bienestar social en España. Madrid: Sequitur.

Negri, A. (1998). El Exilio. Barcelona: El Viejo Topo.

Nozick, R. (1974). Anarquía, estado y utopía. México: Fondo de Cultura Económica.

Raventós Panella, D. (1999). El derecho a la existencia. Barcelona: Ariel.

Raventós Panella, D. (Comp.).(2001). La Renta Básica. Por una ciudadanía más libre, más igualitariay más fraterna. Barcelona: Ariel.

Raventós Panella, D. y Wark, J. (2012). General strike in the Kingdom of Spain: the political economy and basic income. En www.opendemocracy.net. Consultado en Abril 2012. 
Rawls, J. (1995). Teoría de la justicia. Madrid: Fondo de Cultura Económica.

Rodríguez Fernández, J. R. (2011) Los planes de formación en la Administración Pública. Un análisis crítico. Formación profesional. Orientaciones y recursos. Barcelona: Wolters kluwer

Santos, Boaventura de Sousa (2008). La destrucción del Modelo Social Europeo. Rebelión. Disponible en: www.Rebelión.org. Consultado: Noviembre de 2010.

Sanzo González, L. (2005). La introducción de la renta básica en España. Cuadernos de Relaciones Laborales, 23 (2), 123-149.

Schön, D. (1992). La formación de profesionales reflexivos: hacia un nuevo diseño de la enseñanza y el aprendizaje en las profesiones. Barcelona: Paidós.

Silva, T. T. da (2001). Espacios de identidad. Nuevas visiones sobre el curriculum. Barcelona: Octaedro.

Torres, J. (1994). El curriculum oculto. Madrid: Morata.

Taibo, C. (2009). En defensa del decrecimiento. Sobre capitalismo, crisis y barbarie. Madrid: Los libros de la Catarata.

Van Parjis, P. (1995). Real Freedom for All. What (if anything) can justify Capitalism? Oxford: Oxford University Press.

Wacquant, L. (2000). Las cárceles de la miseria. Madrid: Alianza.

Wacquant, L. (2010). Castigar a los pobres. El gobierno neoliberal de la inseguridad social. Barcelona: Gedisa.

Wacquant, L. (2011). Neoliberal penalty at work. A response to my Spanish critics. Revista Española de Sociología, 15, 115-123.

Willis, P. (1988). Aprendiendo a trabajar. Cómo los chicos de clase obrera consiguen trabajos de clase obrera. Madrid: Akal.

Wright, E. O. (1997). Reflexiones sobre el socialismo, capitalismo y marxismo. Palma de Mallorca: Contextos-CCOO.

Wright, E. O. (2001). Propuestas utópicas para reducir la desigualdad de ingresos y riqueza. En Gargarella, R. (Comp.)(2001). Razones para el socialismo. Barcelona: Paidós.

Zinn, H. (1997) La otra historia de los estados unidos. Hondarribia: Hiru. 


\section{Acerca del autor}

\section{Juan Ramón Rodríguez Fernández}

Consejería de Bienestar Social del Principado de Asturias (España). Dirección General de Atención a la Dependencia. Equipo Territorial de Servicios Sociales del Área VII. Pedagogo. Email: juanramon.rodriguezfernandez@asturias.org Licenciado en Ciencias de la Educación y Especialista en Pedagogía social e Intervención socioeducativa por la Universidad de Oviedo (España). Líneas de investigación: Teoría crítica y postcrítica en educación, renta básica, análisis político del discurso educativo.

\section{Acerca de los co-editores del número especial}

\section{Daniel Schugurensky}

Arizona State University

Email: dschugur@asu.edu

Daniel Schugurensky is Full professor at Arizona State University, where he has joint appointment in the School of Public Affairs and the School of Social Transformation. He is the Head of the Area of Justice and Social Inquiry, and the coordinator of the Masters program in social and cultural pedagogy. He has written extensively on youth and adult education, community development and participatory democracy. Among his recent authored and coedited books are Ruptures, continuities and re-learning: The political participation of Latin Americans in Canada (Transformative Learning Centre, University of Toronto, 2006), Four in Ten: Spanish-Speaking Youth and Early School Leaving in Toronto (LARED, 2009), Learning citizenship by practicing democracy: international initiatives and perspectives (Cambridge Scholarly Press, 2010), Paulo Freire (Continuum, 2011), and Volunteer work, informal learning and social action (Sense 2013).

\section{Michael Silver}

Arizona State University

Email: Michael.Silver@asu.edu

Michael Silver is a Research Fellow at the National Center on Education and the Economy and the Center for the Future of Arizona. As a Doctoral Student in Educational Policy and Evaluation, his research focuses on policies affecting educational equity and issues of social justice - particularly those related to historically vulnerable, minority populations. 


\title{
SPECIAL ISSUE Social Pedagogy in the $21^{\text {st }}$ Century education policy analysis archives
}

\begin{abstract}
(c)
SOMERERGHISRESERVED Readers are free to copy, display, and distribute this article, as long as the work is attributed to the author(s) and Education Policy Analysis Archives, it is distributed for noncommercial purposes only, and no alteration or transformation is made in the work. More details of this Creative Commons license are available at http://creativecommons.org/licenses/by-nc-sa/3.0/. All other uses must be approved by the author(s) or EPAA. EPAA is published by the Mary Lou Fulton Institute and Graduate School of Education at Arizona State University Articles are indexed in CIRC (Clasificación Integrada de Revistas Científicas, Spain), DIALNET (Spain), Directory of Open Access Journals, EBSCO Education Research Complete, ERIC, Education Full Text (H.W. Wilson), QUALIS A2 (Brazil), SCImago Journal Rank; SCOPUS, SOCOLAR (China).

Please contribute commentaries at http://epaa.info/wordpress/ and send errata notes to Gustavo E. Fischman fischman@asu.edu

Join EPAA's Facebook community at https://www.facebook.com/EPAAAAPE and Twitter feed@epaa_aape.
\end{abstract}




\section{education policy analysis archives editorial board}

Editor Gustavo E. Fischman (Arizona State University)

Associate Editors: David R. Garcia (Arizona State University), Stephen Lawton (Arizona State University)

Rick Mintrop, (University of California, Berkeley) Jeanne M. Powers (Arizona State University)

Jessica Allen University of Colorado, Boulder

Gary Anderson New York University

Michael W. Apple University of Wisconsin, Madison

Angela Arzubiaga Arizona State University

David C. Berliner Arizona State University

Robert Bickel Marshall University

Henry Braun Boston College

Eric Camburn University of Wisconsin, Madison

Wendy C. Chi* University of Colorado, Boulder

Casey Cobb University of Connecticut

Arnold Danzig Arizona State University

Antonia Darder University of Illinois, UrbanaChampaign

Linda Darling-Hammond Stanford University

Chad d'Entremont Strategies for Children

John Diamond Harvard University

Tara Donahue Learning Point Associates

Sherman Dorn University of South Florida

Christopher Joseph Frey Bowling Green State University

Melissa Lynn Freeman* Adams State College

Amy Garrett Dikkers University of Minnesota

Gene V Glass Arizona State University

Ronald Glass University of California, Santa Cruz

Harvey Goldstein Bristol University

Jacob P. K. Gross Indiana University

Eric M. Haas WestEd

Kimberly Joy Howard* University of Southern California

Aimee Howley Ohio University

Craig Howley Ohio University

Steve Klees University of Maryland

Jaekyung Lee SUNY Buffalo
Christopher Lubienski University of Illinois, UrbanaChampaign

Sarah Lubienski University of Illinois, UrbanaChampaign

Samuel R. Lucas University of California, Berkeley

Maria Martinez-Coslo University of Texas, Arlington

William Mathis University of Colorado, Boulder

Tristan McCowan Institute of Education, London

Heinrich Mintrop University of California, Berkeley

Michele S. Moses University of Colorado, Boulder

Julianne Moss University of Melbourne

Sharon Nichols University of Texas, San Antonio

Noga O'Connor University of Iowa

João Paraskveva University of Massachusetts, Dartmouth

Laurence Parker University of Illinois, UrbanaChampaign

Susan L. Robertson Bristol University

John Rogers University of California, Los Angeles

A. G. Rud Purdue University

Felicia C. Sanders The Pennsylvania State University Janelle Scott University of California, Berkeley

Kimberly Scott Arizona State University

Dorothy Shipps Baruch College/CUNY

Maria Teresa Tatto Michigan State University

Larisa Warhol University of Connecticut

Cally Waite Social Science Research Council

John Weathers University of Colorado, Colorado Springs

Kevin Welner University of Colorado, Boulder

Ed Wiley University of Colorado, Boulder

Terrence G. Wiley Arizona State University

John Willinsky Stanford University

Kyo Yamashiro University of California, Los Angeles

* Members of the New Scholars Board 


\section{archivos analíticos de políticas educativas consejo editorial}

Editor: Gustavo E. Fischman (Arizona State University)

Editores. Asociados Alejandro Canales (UNAM) y Jesús Romero Morante (Universidad de Cantabria)

Armando Alcántara Santuario Instituto de Investigaciones sobre la Universidad y la Educación, UNAM México

Claudio Almonacid Universidad Metropolitana de Ciencias de la Educación, Chile

Pilar Arnaiz Sánchez Universidad de Murcia, España

Xavier Besalú Costa Universitat de Girona, España Jose Joaquin Brunner Universidad Diego Portales, Chile

Damián Canales Sánchez Instituto Nacional para la Evaluación de la Educación, México

María Caridad García Universidad Católica del Norte, Chile

Raimundo Cuesta Fernández IES Fray Luis de León, España

Marco Antonio Delgado Fuentes Universidad Iberoamericana, México

Inés Dussel FLACSO, Argentina

Rafael Feito Alonso Universidad Complutense de Madrid, España

Pedro Flores Crespo Universidad Iberoamericana, México

Verónica García Martínez Universidad Juárez Autónoma de Tabasco, México

Francisco F. García Pérez Universidad de Sevilla, España

Edna Luna Serrano Universidad Autónoma de Baja California, México

Alma Maldonado Departamento de Investigaciones Educativas, Centro de Investigación y de Estudios Avanzados, México

Alejandro Márquez Jiménez Instituto de Investigaciones sobre la Universidad y la Educación, UNAM México

José Felipe Martínez Fernández University of California Los Angeles, USA
Fanni Muñoz Pontificia Universidad Católica de Perú

Imanol Ordorika Instituto de Investigaciones Economicas - UNAM, México

Maria Cristina Parra Sandoval Universidad de Zulia, Venezuela

Miguel A. Pereyra Universidad de Granada, España

Monica Pini Universidad Nacional de San Martín, Argentina

Paula Razquin UNESCO, Francia

Ignacio Rivas Flores Universidad de Málaga, España

Daniel Schugurensky Arizona State University

Orlando Pulido Chaves Universidad Pedagógica Nacional, Colombia

José Gregorio Rodríguez Universidad Nacional de Colombia

Miriam Rodríguez Vargas Universidad Autónoma de Tamaulipas, México

Mario Rueda Beltrán Instituto de Investigaciones sobre la Universidad y la Educación, UNAM México

José Luis San Fabián Maroto Universidad de Oviedo, España

Yengny Marisol Silva Laya Universidad Iberoamericana, México

Aida Terrón Bañuelos Universidad de Oviedo, España

Jurjo Torres Santomé Universidad de la Coruña, España

Antoni Verger Planells University of Amsterdam, Holanda

Mario Yapu Universidad Para la Investigación Estratégica, Bolivia 


\section{arquivos analíticos de políticas educativas conselho editorial}

Editor: Gustavo E. Fischman (Arizona State University)

Editores Associados: Rosa Maria Bueno Fisher e Luis A. Gandin

(Universidade Federal do Rio Grande do Sul)

Dalila Andrade de Oliveira Universidade Federal de Minas Gerais, Brasil

Paulo Carrano Universidade Federal Fluminense, Brasil

Alicia Maria Catalano de Bonamino Pontificia Universidade Católica-Rio, Brasil

Fabiana de Amorim Marcello Universidade Luterana do Brasil, Canoas, Brasil

Alexandre Fernandez Vaz Universidade Federal de Santa Catarina, Brasil

Gaudêncio Frigotto Universidade do Estado do Rio de Janeiro, Brasil

Alfredo M Gomes Universidade Federal de Pernambuco, Brasil

Petronilha Beatriz Gonçalves e Silva Universidade Federal de São Carlos, Brasil

Nadja Herman Pontificia Universidade Católica -Rio Grande do Sul, Brasil

José Machado Pais Instituto de Ciências Sociais da Universidade de Lisboa, Portugal

Wenceslao Machado de Oliveira Jr. Universidade Estadual de Campinas, Brasil
Jefferson Mainardes Universidade Estadual de Ponta Grossa, Brasil

Luciano Mendes de Faria Filho Universidade Federal de Minas Gerais, Brasil

Lia Raquel Moreira Oliveira Universidade do Minho, Portugal

Belmira Oliveira Bueno Universidade de São Paulo, Brasil

António Teodoro Universidade Lusófona, Portugal

Pia L. Wong California State University Sacramento, U.S.A

Sandra Regina Sales Universidade Federal Rural do Rio de Janeiro, Brasil

Elba Siqueira Sá Barreto Fundação Carlos Chagas, Brasil

Manuela Terrasêca Universidade do Porto, Portugal

Robert Verhine Universidade Federal da Bahia, Brasil

Antônio A. S. Zuin Universidade Federal de São Carlos, Brasil 